\title{
'Read and cite hair et al.`: how the work of Joseph F. Hair impacts us in Malaysia
}

\begin{abstract}
There are not many global experts on multivariate data analysis whose work can benefit researchers and students from all over the world; Professor Joseph F. Hair is one of them. Undoubtedly, his work has had and continues to have a significant impact on marketing, business, and social science research. This paper is a personal narrative dedicated to Joseph Hair to express our gratitude to and admiration of his personality, passion, and work. We wish to acknowledge how his work has played an important role in enhancing the understanding of multivariate data analysis of thousands of us in Malaysia and shaping our research development. We hope to perpetuate his legacy by learning and sharing with others the ongoing advancement of CB-SEM and PLS-SEM, as well as quantitative data analysis. In addition, we pray that he remains healthy, strong, and active in the research community in many more years to come.
\end{abstract}

Keyword: Malaysia; mySEM; JASEM; Joseph F. Hair; PLS-SEM 